\title{
Performance Study of CdS/Co-Doped-CdSe Quantum Dot Sensitized Solar Cells
}

\author{
Xiaoping Zou, Sheng He, Gongqing Teng, and Chuan Zhao \\ Beijing Key Laboratory for Sensor, Ministry of Education Key Laboratory for Modern Measurement and Control Technology, \\ Research Center for Sensor Technology, and School of Applied Sciences, Beijing Information Science and Technology University, \\ Jianxiangqiao Campus, Beijing 100101, China
}

Correspondence should be addressed to Xiaoping Zou; xpzou2005@gmail.com

Received 19 January 2014; Revised 2 April 2014; Accepted 2 April 2014; Published 16 April 2014

Academic Editor: William W. Yu

Copyright (C) 2014 Xiaoping Zou et al. This is an open access article distributed under the Creative Commons Attribution License, which permits unrestricted use, distribution, and reproduction in any medium, provided the original work is properly cited.

In order to optimize the charge transfer path in quantum dot sensitized solar cells (QDSCs), we employed successive ionic layer adsorption and reaction method to dope CdSe with Co for fabricating CdS/Co-doped-CdSe QDSCs constructed with CdS/Codoped-CdSe deposited on mesoscopic $\mathrm{TiO}_{2}$ film as photoanode, $\mathrm{Pt}$ counter electrode, and sulfide/polysulfide electrolyte. After Co doping, the bandgap of CdSe quantum dot decreases, and the conduction band and valence band all improve, forming a cascade energy level which is more conducive to charge transport inside the solar cell and reducing the recombination of electron-hole thus improving the photocurrent and ultimately improving the power conversion efficiency. This work has not been found in the literature.

\section{Introduction}

Quantum dot sensitized solar cells (QDSCs) have received wide attention recently. Quantum dots (QDs) have significant advantages over conventional organic dyes, such as tunability of the bandgap [1,2], extremely high absorption coefficient [3], generation of multiple electron carriers under high energy excitation [4], and delivery of hot electrons $[5,6]$. Especially, the theoretical efficiency of QDSCs is estimated up to $44 \%$ due to the multiple exciton generation effect. However, the best record power conversion efficiency of QDSCs remains quite low.

Controlling conductivity via doping in semiconductor quantum dots is an important part of nanoparticle research. Recent effort to improve the power conversion efficiency is to modify the intrinsic property of semiconductor nanocrystals by introducing dopants $[7,8]$. By doping optically active transition metal ions, it is possible to modify the electronic and photophysical properties of QDs [9-13]. The dopant significantly changes the electronic structure of the quantum dot. Santanu et al. explored CdSe quantum dots doping with indium and tin. In agreement with the expected n-type behavior, the photoluminescence (PL) of both indium and tin doped samples exhibits significantly steeper temperature dependence, compared to undoped CdSe quantum dots [14]. Pralay and Prashant employed $\mathrm{Mn}^{2+}$ doping of CdS; they had succeeded in significantly improving the performance of QDSCs. QDSCs constructed with Mn-doped-CdS/CdSe deposited on mesoscopic $\mathrm{TiO}_{2}$ film as photoanode deliver power conversion efficiency of 5.4\% [15]. Huang et al. employed successive ionic layer adsorption and reaction method to dope $\mathrm{PbS}$ with $\mathrm{Cu}^{2+}$. The power conversion efficiency $(\sim 2.01 \%)$ coupled with a remarkably superior short circuit current density $\left(21 \mathrm{~mA} / \mathrm{cm}^{2}\right)$ was achieved in the resulting $\mathrm{Cu}$-doped-PbS/CdS quantum dot sensitized solar cells [16]. Lee et al. reported on a PbS:Hg QD-sensitized solar cell with an unprecedentedly high $J_{\mathrm{SC}}$ of $30 \mathrm{~mA} / \mathrm{cm}^{2}$; the power conversion efficiency of $5.6 \%$ is demonstrated at one sun illumination [17]. Wang et al. used electrochemical deposition method to deposit Co doped CdSe quantum dots on $\mathrm{TiO}_{2}$ single-crystal nanorods array [18]. On the one hand, CdSe doping with Co can tune its bandgap, so that the absorption in the visible light range is enhanced, the absorption range gets broadened, and then improves the light utilization efficiency. On the other hand, Co doping can increase the carrier concentration and the rate of electron 
transfer and increase the efficiency of electron collection; thus the photocurrent density is increased.

Inspired by the previous doping on CdSe and that Co doping has excellent effect on quantum dot sensitized solar cells, we used successive ionic layer adsorption and reaction (SILAR) method to assemble into CdS/Co-doped-CdSe quantum dot sensitized solar cells. Doping CdSe with $\mathrm{Co}$ significantly improves the short circuit current density $\left(J_{\mathrm{SC}}\right)$ and open circuit voltage $\left(V_{\mathrm{OC}}\right)$ and eventually increases the power conversion efficiency. Using SILAR method, doping $\mathrm{CdSe}$ with Co, and preparing CdS/Co-doped-CdSe quantum dot sensitized solar cells have mot been reported in the literature.

\section{Experimental}

2.1. Preparation of CdS/Co-Doped-CdSe Co-Sensitized Mesoporous $\mathrm{TiO}_{2}$ Photoanode. The mesoporous $\mathrm{TiO}_{2}$ photoanodes were in situ sensitized by CdS and CdSe QDs grown by successive ionic layer adsorption and reaction (SILAR) method [19]. Specifically, CdS was prepared by cadmium nitrate $\left(\mathrm{Cd}\left(\mathrm{NO}_{3}\right)_{2}\right)$ and sodium sulfide $\left(\mathrm{Na}_{2} \mathrm{~S}\right)$. $0.1 \mathrm{M} \mathrm{Cd}\left(\mathrm{NO}_{3}\right)_{2}$ in ethanol and $0.1 \mathrm{M} \mathrm{Na}_{2} \mathrm{~S}$ in methanol were used as cation source and anion source, respectively. Each SILAR cycle consists of successive immersion of the FTO glass photoanode, which was precoated with a transparent $\mathrm{TiO}_{2}$ layer, in metal cation and sulfide anion solutions for 5 min. Following each immersion, the $\mathrm{TiO}_{2}$ photoanodes were rinsed with ethanol and methanol, respectively, and then dried with a $\mathrm{N}_{2}$ gun, respectively. To incorporate doping of $\mathrm{Co}^{2+}$, cobalt acetate $\left(\mathrm{C}_{4} \mathrm{H}_{6} \mathrm{CoO}_{4}\right)$ was mixed with cadmium nitrate. Co-doped-CdSe was prepared by $\mathrm{Cd}\left(\mathrm{NO}_{3}\right)_{2}$ and sodium selenosulphate $\left(\mathrm{Na}_{2} \mathrm{SeSO}_{3}\right)$ mixing with $\mathrm{C}_{4} \mathrm{H}_{6} \mathrm{CoO}_{4}$. The $\mathrm{Na}_{2} \mathrm{SeSO}_{3}$ aqueous solution was prepared by refluxing $0.06 \mathrm{M}$ Se in an aqueous solution of $0.12 \mathrm{M} \mathrm{Na}_{2} \mathrm{SO}_{3}$ at $70^{\circ} \mathrm{C}$ for $7 \mathrm{~h} \mathrm{[20].} \mathrm{The} \mathrm{SILAR} \mathrm{processes} \mathrm{of} \mathrm{Co-doped-CdSe} \mathrm{were}$ similar to those of $\mathrm{CdS} \mathrm{QDs}$. The $\mathrm{TiO}_{2} / \mathrm{CdS}$ photoanodes were successively immersed in ethanol solution containing $\mathrm{Cd}\left(\mathrm{NO}_{3}\right)_{2}$ and $\mathrm{C}_{4} \mathrm{H}_{6} \mathrm{CoO}_{4}$ for $5 \mathrm{~min}$ at room temperature, and then in $\mathrm{Na}_{2} \mathrm{SeSO}_{3}$ aqueous solution for $0.5 \mathrm{~h}$ at $50^{\circ} \mathrm{C}$. Following each immersion, rinsing and drying were undertaken using pure solvent and a $\mathrm{N}_{2}$ gun, respectively. All these processes are termed as one SILAR cycle of CdSe.

2.2. Fabrication of QDSCs. The polysulfide electrolyte used in this work was prepared freshly by dissolving $1 \mathrm{M}$ sodium sulfide and $1 \mathrm{M}$ sulfur in ultrapure water. The CdS/Codoped-CdSe cosensitized $\mathrm{TiO}_{2}$ photoanode and Pt-counter electrode were assembled into a sandwich cell using a parafilm spacer. The active area of QDSCs was $0.25 \mathrm{~cm}^{2}$. Solar cell performance was evaluated under simulated AM 1.5 irradiation conditions.

\section{Results and Discussion}

We firstly studied the influence of different Co doping concentration on CdS/Co-doped-CdSe quantum dots sensitized solar cells' performance. Here, we doped Co in CdSe with

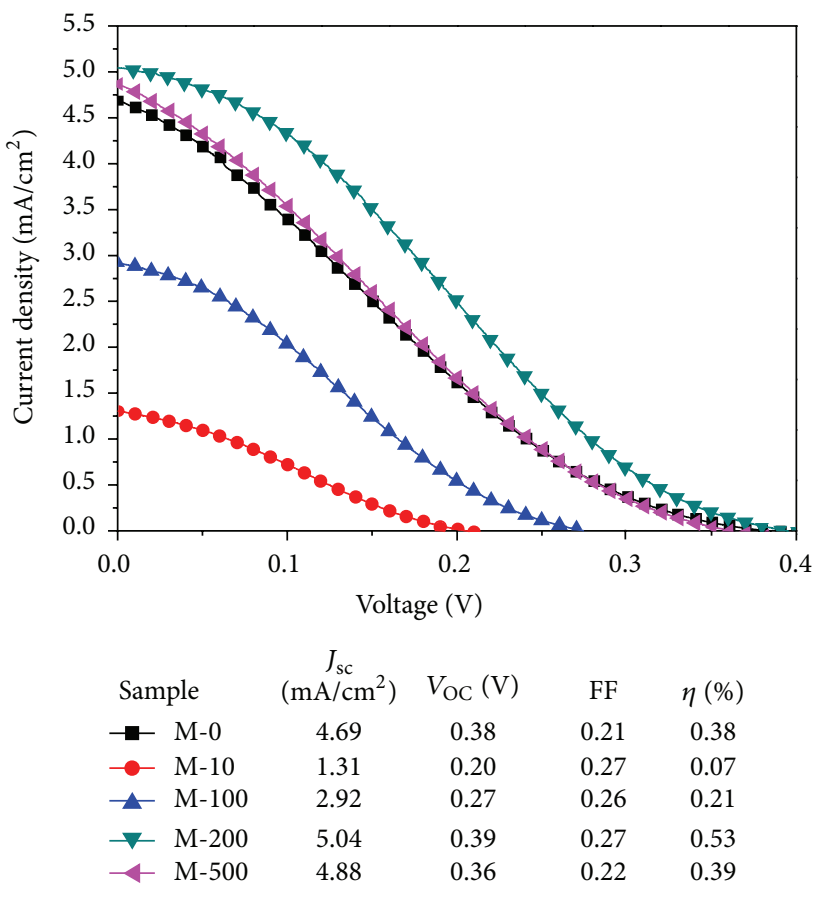

Figure 1: The $J-V$ curves of different working electrodes based on Co doped CdSe. The corresponding parameters are shown in the upper right corner.

different doping concentration. M-10 represents the ratio of Co molarity versus Cd molarity as 1:10, and the total SILAR cycles include 4 cycles CdS and 4 cycles Co-doped-CdSe. The same is true to others. M-0 represents the undoped CdSe.

Figure 1 shows the $J-V$ curves of different working electrodes based on Co doped CdSe. The corresponding parameters are shown in the upper right corner. From Figure 1, we can find that due to the difference in Co doping concentration, the performance of some Co doped solar cells is better than the undoped; however, some Co doped solar cells have worse performance. From the solar cells' performance parameters in the upper right corner, it is easy to find the laws: with the decrease in Co doping concentration (decreasing from 1:10 to 1:500), the short circuit current density $\left(J_{\mathrm{SC}}\right)$, open circuit voltage $\left(V_{\mathrm{OC}}\right)$, fill factor $(\mathrm{FF})$, and power conversion efficiency all have a basic trend of first increasing and then decreasing. When Co doping concentration is $1: 200$, they all obtain the maximum values; they are $5.04 \mathrm{~mA} / \mathrm{cm}^{2}, 0.39 \mathrm{~V}, 0.27,0.53 \%$, respectively. When Co doping concentration is no more than $1: 200$, the Co doped solar cells have better performance than the undoped. This maybe the doping concentrations of $1: 10$ and $1: 100$ belonging to heavy doping for Co elements; they introduce a lot of recombination centers, and result in Co doped solar cells with these doping concentrations having worse performances than the undoped.

On the basis of the optimal doping ratio in the front, we discussed CdS SILAR cycles on the performance of CdS/Codoped-CdSe. S-2 represents the SILAR cycles of CdS as 2 and the total SILAR cycles as including 2 cycles $\mathrm{CdS}$ and 4 cycles 


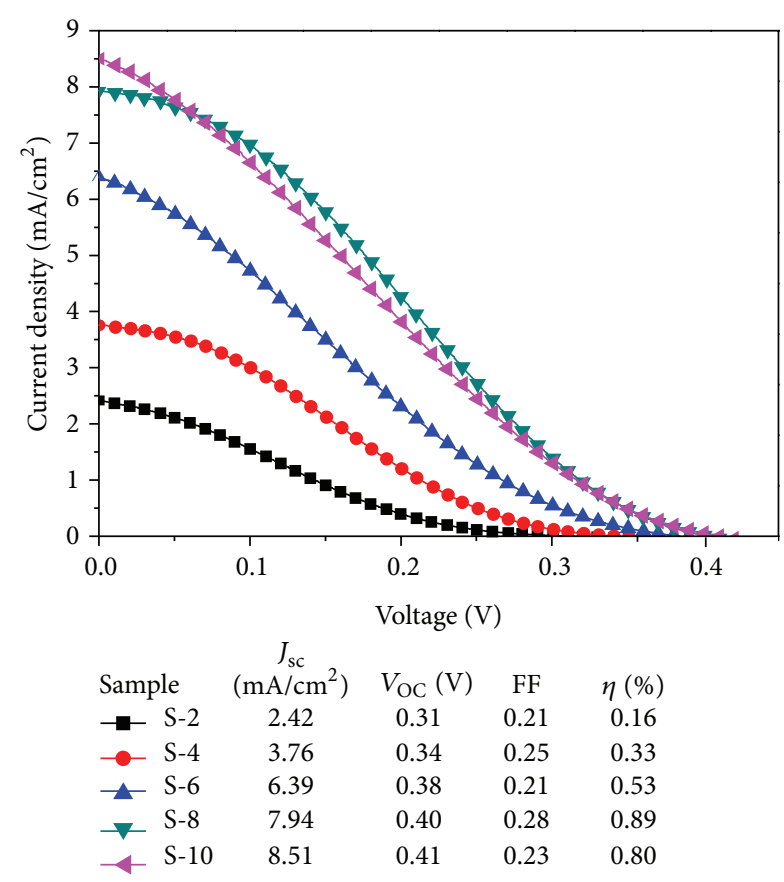

FIgURE 2: The $J-V$ curves of different working electrodes based on different CdS SILAR cycles. The corresponding parameters are shown in the upper right corner.

Co-doped-CdSe. The Co doping concentration is all 1:200, and the SILAR cycles of CdSe are all 4 . The same is true to others.

Figure 2 shows the $J-V$ curves of different working electrodes based on different CdS SILAR cycles. The corresponding parameters are shown in the upper right corner. It is easy to find that with the increase in CdS SILAR cycles, $J_{\mathrm{SC}}$ and $V_{\mathrm{OC}}$ consistently increase. When CdS SILAR cycles are 10 , they all reach the maximum; they are $8.51 \mathrm{~mA} / \mathrm{cm}^{2}$, $0.41 \mathrm{~V}$, respectively. But taking the impact of the fill factor into account, the power conversion efficiency gets the maximum when CdS SILAR cycle is 8 ; it is $0.89 \%$.

Through the above experiments, we found that CdSe doping with Co has a great promotion effect on the performance of $\mathrm{CdS} / \mathrm{CdSe}$ quantum dots sensitized solar cells. So a series of comparative experiments among $\mathrm{CdS} / \mathrm{Co}$-doped$\mathrm{CdSe}$ and undoped CdS/CdSe quantum dots sensitized solar cells was conducted to systematically analyze the mechanism of CdSe doping with Co having influence on the performance of CdS/CdSe quantum dots sensitized solar cells.

Figure 3 shows the top view SEM images of (a) bare $\mathrm{TiO}_{2}$ and (b) $\mathrm{TiO}_{2}$ mesoporous film deposited by CdS/Codoped-CdSe. From (a) we can find the morphology of $\mathrm{TiO}_{2}$ particles in $20 \mathrm{~nm}$ sizes. The morphology of semiconductor films deposited on mesoscopic $\mathrm{TiO}_{2}$ films is shown in (b). It is easy to find that after depositing quantum dots, the surface of mesoscopic $\mathrm{TiO}_{2}$ film becomes much rougher. And due to the adsorption of quantum dots on the surface, the size of $\mathrm{TiO}_{2}$ particle becomes bigger, too.

Figure 4 shows the low-magnification and highmagnification TEM images of CdS/Co-doped-CdSe films.
A clear morphology with a grain size of QDs nanoparticles ranges from 4 to $6 \mathrm{~nm}$ remained on the surface of $\mathrm{TiO}_{2}$ nanoparticles after the doped precursor solution immersion, indicating that CdS/Co-doped-CdSe QDs are markedly adsorbed on the surface of $\mathrm{TiO}_{2}$ nanoparticles.

Figure 5 shows the XRD patterns of CdS/Co-doped-CdSe films. It is found that after Co doping, the diffraction peak of CdSe slightly shifted from $41.96^{\circ}$ to $42.40^{\circ}$. It is suggested that the Co doping leads to the lattice distortion of CdSe, which exhibits the formation of $\mathrm{Co}$ in the as-prepared samples. Although only the most intense peak of the Co doped CdSe was observed, this is due to the relatively low quantity of $\mathrm{Co}$ dopant.

The UV-visible absorption spectra of CdS(4)/Co-CdSe(4) and $\mathrm{CdS}(4) / \mathrm{CdSe}(4)$ photoanodes are shown in Figure 6. It is found that in the same wavelength range, the photoanode of CdS(4)/Co-CdSe(4) has stronger light absorption intensity than the undoped photoanode; this is corresponding to an increase in current density of Co-doped solar cell. And the addition of Co atoms results in a red shift of the first exciton absorption peaks. An alternative source of the spectral shifts can be associated with electronic doping by the impurities [21].

The incident-photon-to-carrier conversion efficiency (IPCE) recorded at different incident light wavelength for QDSCs that employ CdS(8)/CdSe(4) and CdS(8)/Co$\mathrm{CdSe}(4)$ photoanodes is shown in Figure 7. It is found that in the wavelength range of $350-475 \mathrm{~nm}$, the maximum IPCE value increases from $42 \%$ of the undoped to $45 \%$ of the Co-doped solar cell. In the wavelength range of $475-675 \mathrm{~nm}$, the Co-doped solar cell has higher IPCE than the undoped solar cell. This is consistent with the change rule of previous absorption spectra and current density.

The diagram of Co doping to the adjustment of CdSe energy level is shown in Figure 8. It is finding that after Co doping, the bandgap of CdSe quantum dot decreases, the conduction band and valence band all improve, forming a cascade energy level which is more conducive to charge transport inside the solar cell $[22,23]$. That is advantageous to the electron injection and hole-recovery, reducing the recombination of electron-hole, and improving the ability of photoanode to capture light thus improving the photocurrent and ultimately improving the power conversion efficiency. This is consistent with the experimental results.

\section{Conclusions}

In summary, SILAR method was used to dope CdSe with Co for fabricating CdS/Co-doped-CdSe quantum dots sensitized solar cells. CdSe doping with Co has a great promotion effect on the performance of CdS/CdSe quantum dots sensitized solar cells, mainly reflected in the improvement of current density and fill factor. After Co doping, the bandgap of CdSe quantum dot decreases, the conduction band and valence band all improve, forming a cascade energy level which is more conducive to charge transport inside the solar cell and reducing the recombination of electron-hole thus improving the photocurrent and ultimately improving 


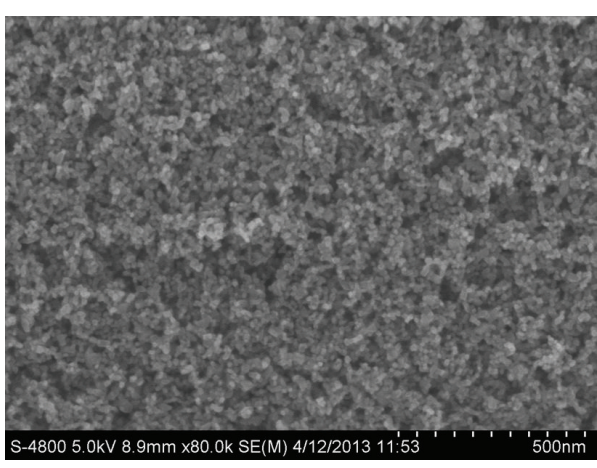

(a)

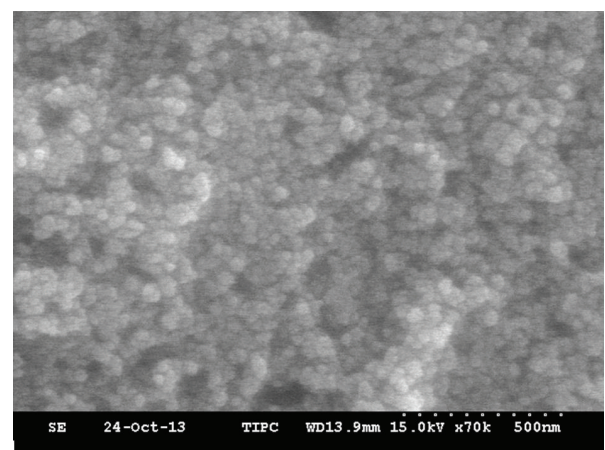

(b)

FIgUre 3: SEM images of (a) bare $\mathrm{TiO}_{2}$ and (b) $\mathrm{TiO}_{2}$ mesoporous film deposited by CdS/Co-doped-CdSe.

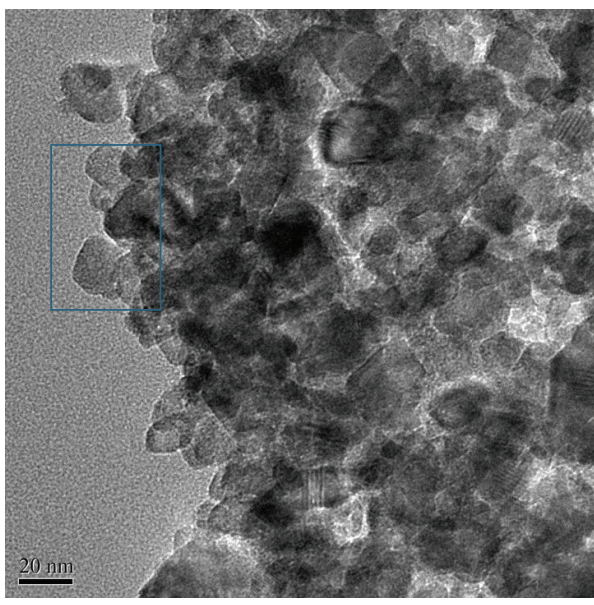

(a)

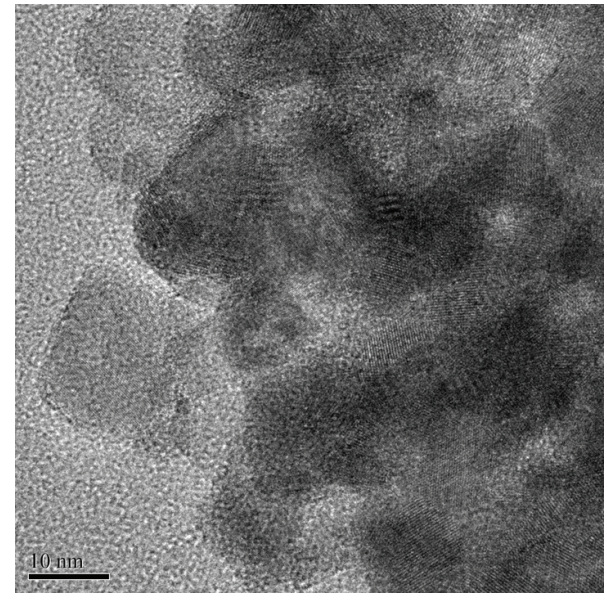

(b)

FIgURE 4: The TEM images of CdS/Co-doped-CdSe films: (a) low-magnification, (b) high-magnification.

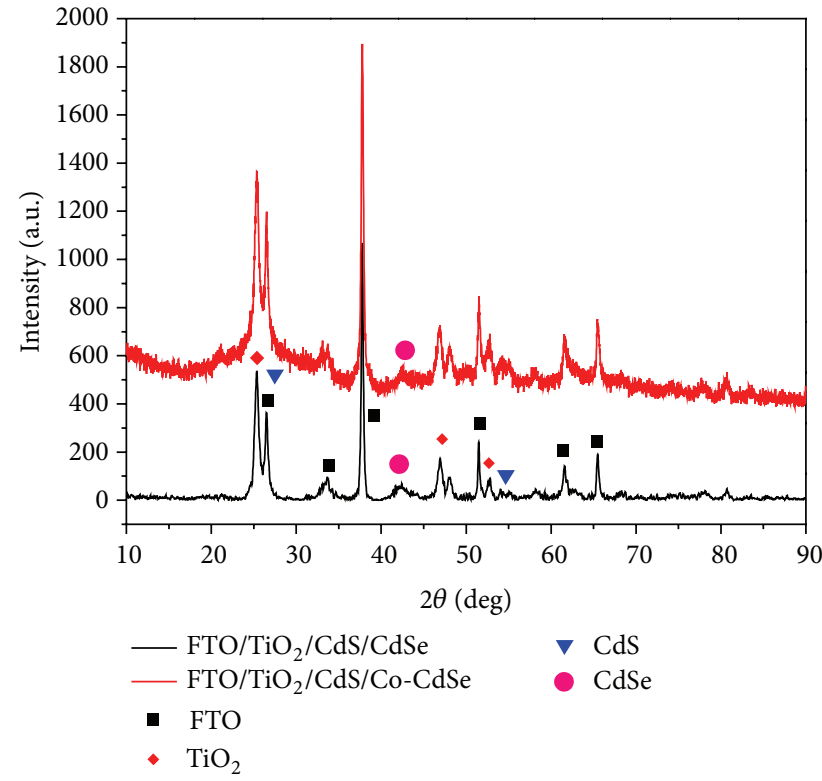

FIgURE 5: The XRD patterns of CdS/Co-doped-CdSe films.

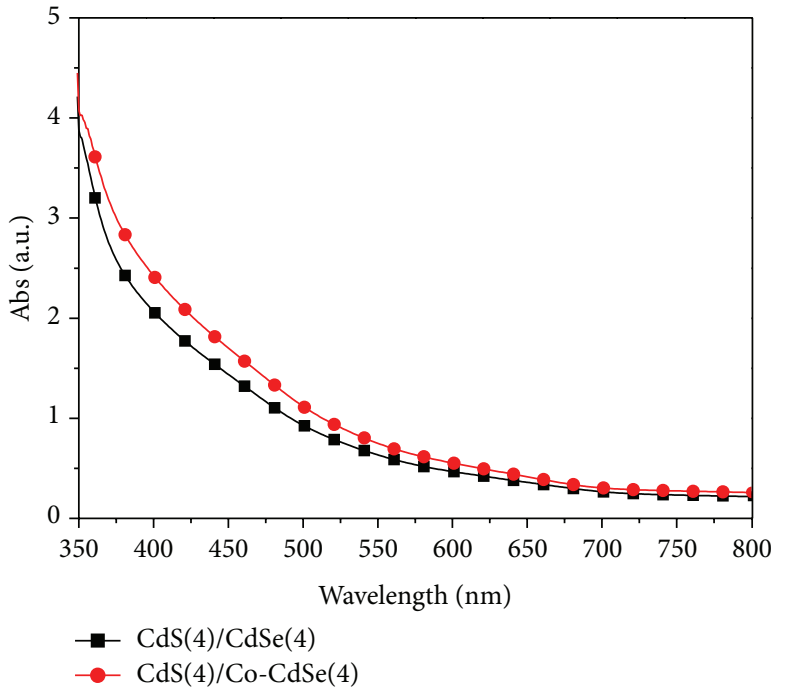

FIGURE 6: The UV-visible absorption spectra of CdS(4)/Co-CdSe(4) and $\mathrm{CdS}(4) / \mathrm{CdSe}(4)$ photoanodes. 


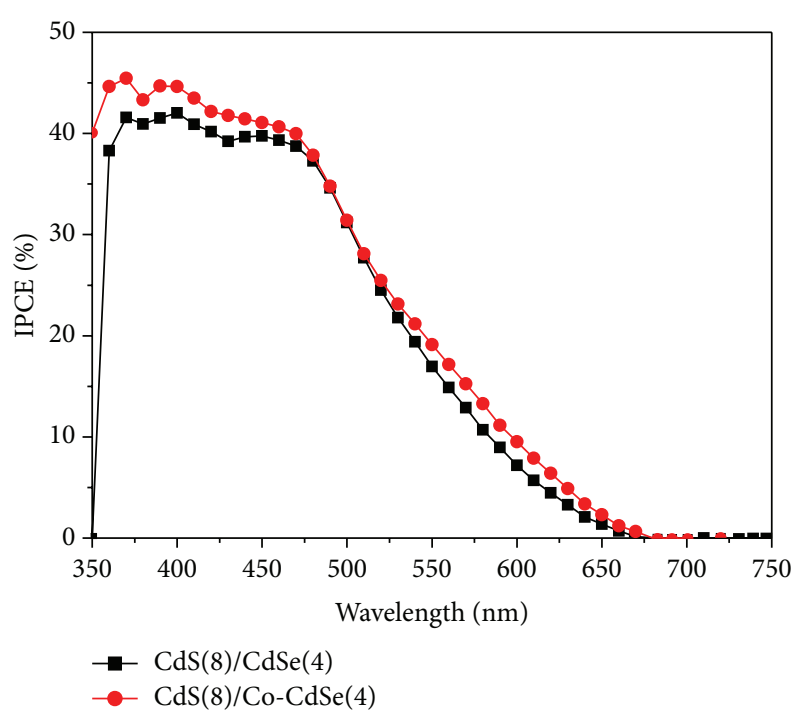

Figure 7: IPCE spectra for $\mathrm{CdS}(8) / \mathrm{CdSe}(4)$ and $\mathrm{CdS}(8) / \mathrm{Co}-$ $\mathrm{CdSe}(4)$ (Pt counter electrode and aqueous $1 \mathrm{M} \mathrm{S}^{2-} / 1 \mathrm{MS}$ as electrolyte).

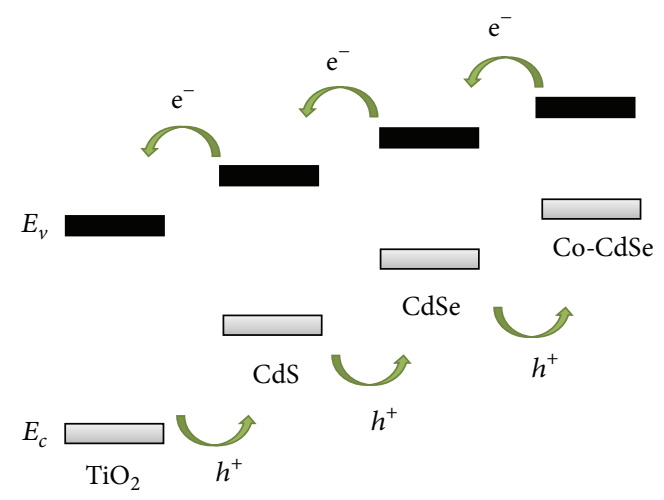

FIGURE 8: The diagram of Co doping to the adjustment of CdSe energy level.

the power conversion efficiency. This work provides a new approach of improving the power conversion efficiency of QDSCs.

\section{Conflict of Interests}

The authors declare that there is no conflict of interests regarding the publication of this paper.

\section{Acknowledgments}

This work was partially supported by Key Project of Beijing Natural Science Foundation (3131001), Key Project of Natural Science Foundation of China (91233201 and 61376057), Key Project of Beijing Education Committee Science \& Technology Plan (KZ201211232040), State 863 Plan of MOST of PR China (2011AA050527), Beijing National Laboratory for Molecular Sciences (BNLMS2012-21), State Key Laboratory for New Ceramic and Fine Processing of Tsinghua University (KF1210), Key Laboratory for Renewable Energy and Gas Hydrate of Chinese Academy of Sciences (y207ka1001), Beijing Key Laboratory for Sensors of BISTU (KF20131077208) and Beijing Key Laboratory for photoelectrical measurement of BISTU (GDKF2013005).

\section{References}

[1] C. B. Murray, D. J. Norris, and M. G. Bawendi, "Synthesis and characterization of nearly monodisperse $\mathrm{CdE}(\mathrm{E}=\mathrm{S}$, Se, Te) semiconductor nanocrystallites," Journal of the American Chemical Society, vol. 115, no. 19, pp. 8706-8715, 1993.

[2] D. D. Sarma, A. Nag, P. K. Santra, A. Kumar, S. Sapra, and P. Mahadevan, "Origin of the enhanced photoluminescence from semiconductor CdSeS nanocrystals," The Journal of Physical Chemistry Letters, vol. 1, no. 14, pp. 2149-2153, 2010.

[3] W. W. Yu, L. H. Qu, W. Z. Guo, and X. G. Peng, "Experimental determination of the extinction coefficient of CdTe, CdSe and CdS nanocrystals," Chemistry of Materials, vol. 16, no. 3, pp. 560-560, 2004.

[4] M. C. Beard, "Multiple exciton generation in semiconductor quantum dots," The Journal of Physical Chemistry Letters, vol. 2, no. 11, pp. 1282-1288, 2011.

[5] A. Pandey and P. Guyot-Sionnest, "Hot electron extraction from colloidal quantum dots," The Journal of Physical Chemistry Letters, vol. 1, no. 1, pp. 45-47, 2010.

[6] W. A. Tisdale, K. J. Williams, B. A. Timp, D. J. Norris, E. S. Aydil, and X.-Y. Zhu, "Hot-electron transfer from semiconductor nanocrystals," Science, vol. 328, no. 5985, pp. 1543-1547, 2010.

[7] N. Pradhan and D. D. Sarma, "Advances in light-emitting doped semiconductor nanocrystals," The Journal of Physical Chemistry Letters, vol. 2, no. 21, pp. 2818-2826, 2011.

[8] V. Chikan, "Challenges and prospects of electronic doping of colloidal quantum dots: case study of CdSe," The Journal of Physical Chemistry Letters, vol. 2, no. 21, pp. 2783-2789, 2011.

[9] R. N. Bhargava, D. Gallagher, X. Hong, and A. Nurmikko, "Optical properties of manganese-doped nanocrystals of $\mathrm{ZnS}$," Physical Review Letters, vol. 72, no. 3, pp. 416-419, 1994.

[10] S. Jana, B. B. Srivastava, and N. Pradhan, "Correlation of dopant states and host bandgap in dual-doped semiconductor nanocrystals," The Journal of Physical Chemistry Letters, vol. 2, no. 14, pp. 1747-1752, 2011.

[11] R. Beaulac, P. I. Archer, S. T. Ochsenbein, and D. R. Gamelin, " $\mathrm{Mn}^{2+}$-doped CdSe quantum dots: new inorganic materials for spin-electronics and spin-photonics," Advanced Functional Materials, vol. 18, no. 24, pp. 3873-3891, 2008.

[12] R. Beaulac, P. I. Archer, and D. R. Gamelin, "Luminescence in colloidal $\mathrm{Mn}^{2+}$-doped semiconductor nanocrystals," Journal of Solid State Chemistry, vol. 181, no. 7, pp. 1582-1589, 2008.

[13] R. Zeng, M. Rutherford, R. Xie, B. Zou, and X. Peng, "Synthesis of highly emissive Mn-Doped ZnSe nanocrystals without pyrophoric reagents," Chemistry of Materials, vol. 22, no. 6, pp. 2107-2113, 2010.

[14] R. Santanu, T. Christopher, F. Fadzai, D. Pinar, and C. Viktor, "Progress toward producing n-type CdSe quantum dots: tin and indium doped CdSe quantum dots," Journal of Physical Chemistry C, vol. 113, no. 30, pp. 13008-13015, 2009.

[15] K. S. Pralay and V. K. Prashant, "Mn-doped quantum dot sensitized solar cells: a strategy to boost efficiency over 5\%," 
Journal of the American Chemical Society, vol. 134, no. 5, pp. 2508-2511, 2012.

[16] Z. B. Huang, X. P. Zou, and H. Q. Zhou, "A strategy to achieve superior photocurrent by $\mathrm{Cu}$-doped quantum dot sensitized solar cells," Materials Letters, vol. 95, pp. 139-141, 2013.

[17] J. W. Lee, D. Y. Son, T. K. Ahn et al., "Quantum-dot-sensitized solar cell with unprecedentedly high photocurrent," Scientific Reports, vol. 3, article 1050, 2013.

[18] H. Wang, B. H. Wang, Y. X. Hu et al., "A method for Co-doped CdSe quantum-dot sensitized $\mathrm{TiO}_{2}$ nano-rod photo-electrode and its preparation method," China Patent, Application Number 201210234979, July 2012.

[19] Y. Zhang, J. Zhu, X. Yu, J. Wei, L. Hu, and S. Dai, “The optical and electrochemical properties of CdS/CdSe co-sensitized $\mathrm{TiO}_{2}$ solar cells prepared by successive ionic layer adsorption and reaction processes," Solar Energy, vol. 86, no. 3, pp. 964-971, 2012.

[20] Y. Lee and Y. Lo, "Highly efficient quantum-dot-sensitized solar cell based on co-sensitization of CdS/CdSe," Advanced Functional Materials, vol. 19, no. 4, pp. 604-609, 2009.

[21] D. Mocatta, G. Cohen, J. Schattner, O. Millo, E. Rabani, and U. Banin, "Heavily doped semiconductor nanocrystal quantum dots," Science, vol. 332, no. 6025, pp. 77-81, 2011.

[22] C.F. Chi, H.W. Cho, H. Teng et al., "Energy level alignment, electron injection, and charge recombination characteristics in CdS/CdSe cosensitized $\mathrm{TiO}_{2}$ photoelectrode," Applied Physics Letters, vol. 98, Article ID 012101, 2011.

[23] Y. Lee, C. Chi, and S. Liau, "CdS/CdSe Co-Sensitized $\mathrm{TiO}_{2}$ photoelectrode for efficient hydrogen generation in a photoelectrochemical cell," Chemistry of Materials, vol. 22, no. 3, pp. 922927, 2010. 

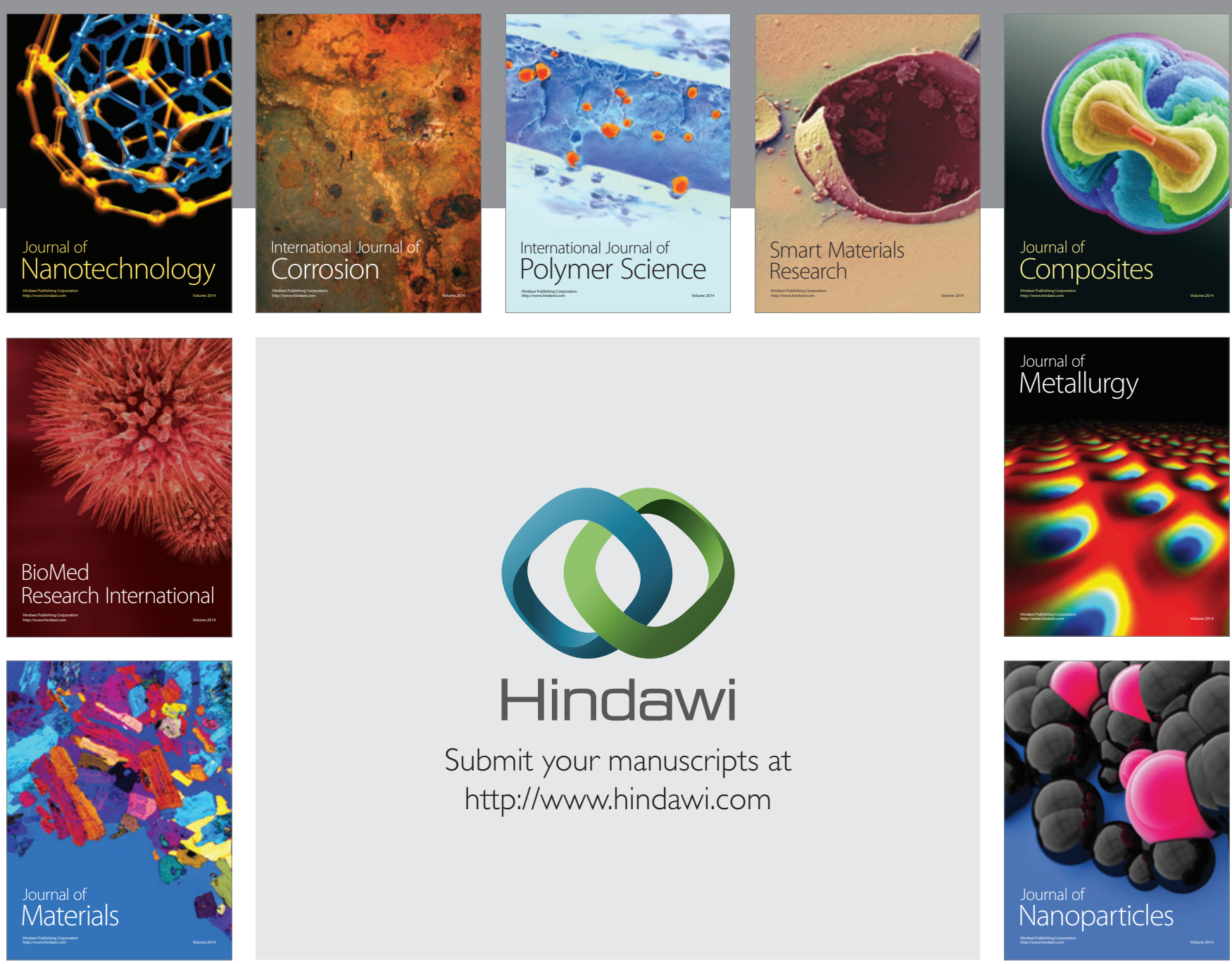

Submit your manuscripts at http://www.hindawi.com
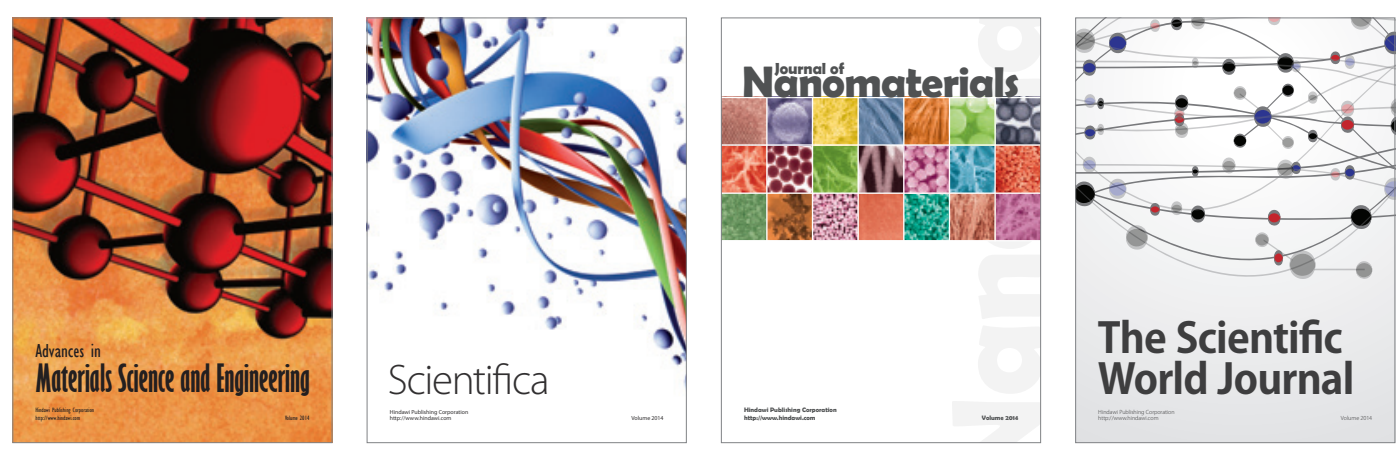

\section{The Scientific World Journal}
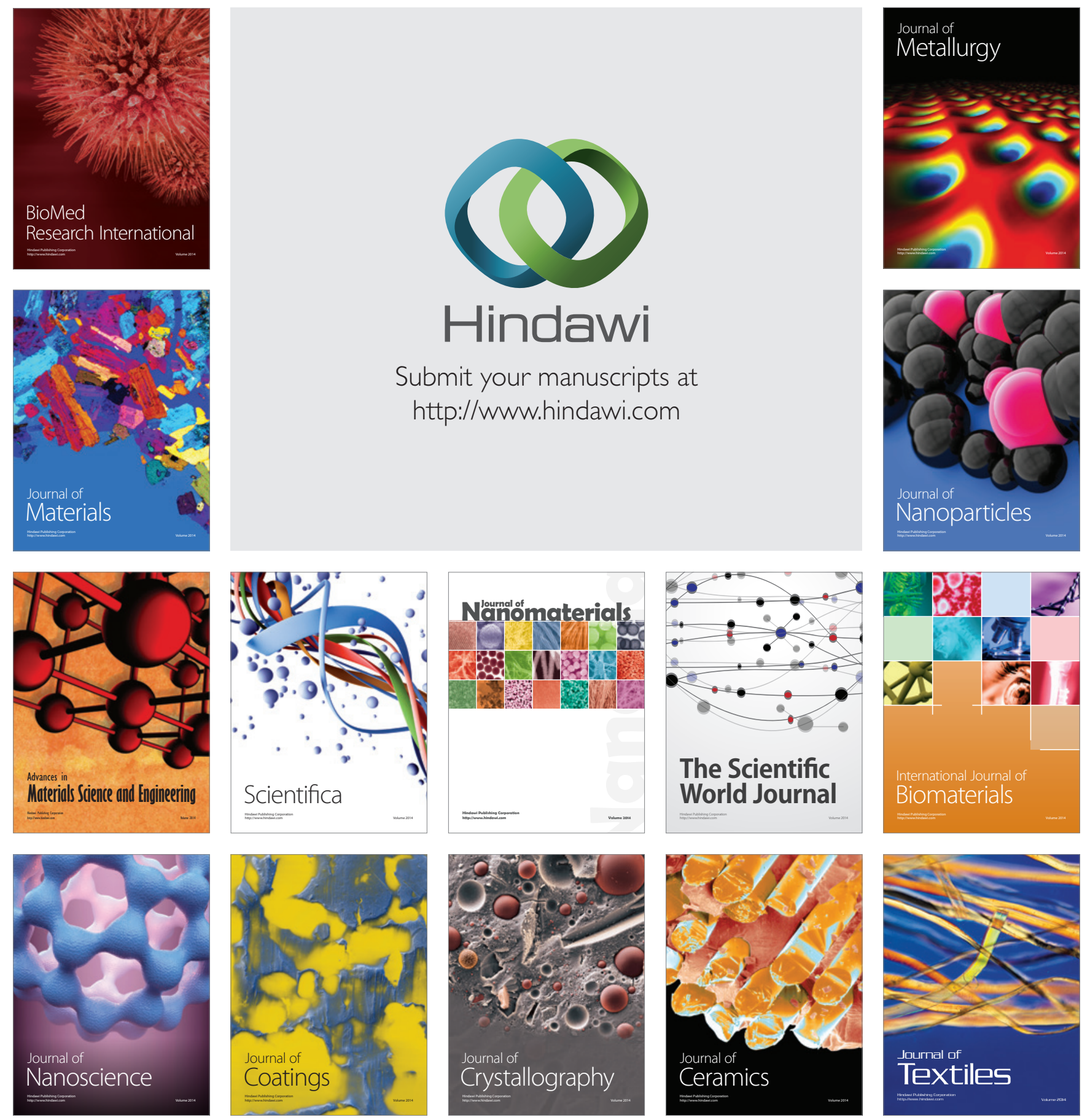